\title{
Three phases microextraction procedure for determination of isothiazolin biocides in adhesives for food packaging materials
}

\author{
M. Rosero-Moreano ${ }^{1,2}$, E. Canellas ${ }^{1,3}$, C. Nerín ${ }^{1}$ \\ ${ }^{1}$ Grupo Universitario de Investigación en Analítica (GUIA) \\ Instituto de Investigación en Ingeniería de Aragón (I3A). \\ Universidad de Zaragoza, Mariano Esquillor s/n, 50018, Zaragoza, Spain. \\ Tel. +34-657 912137, Fax+34-976 762388, e-mail: milton.rosero@ucaldas.edu.co \\ ${ }^{2}$ Universidad de Caldas, Departamento de Química \\ Calle 65 No. 26-10 Sede Principal A.A. 275 Manizales-Caldas-Colombia. \\ ${ }^{3}$ SAMTACK Adhesivos Industriales, Esparreguera (Barcelona, España)
}

\begin{abstract}
The use of biocides in adhesives is widely extended. However, when adhesives are used in food packaging materials, it is important to determine their concentration not only in the packaging materials but also in migration tests, in order to ensure the food safety. Isothiazolin derivatives are low volatile compounds and often used for this purpose. However, the analytical sensitivity is very poor either in GC-MS or in HPLC-UV and an enrichment step is required. The present study deals with the development of a liquid microextraction procedure for enhancing the sensitivity of the determination of 2-methyl-4-isothiazolin-3-one (MIT) and 5-chloro-2-methyl4-isothiazolin-3-one (CMIT) in adhesives and food simulants. The procedure involves three phases and a semipermeable polypropylene (PP) membrane which contains 1-octanol as organic phase. The donor and acceptor phases are aqueous acidic and alkaline media respectively and the final liquid phase is analyzed by RP-HPLC-UV. The detection limits of these biocides are 0.037 and $0.147 \mu \mathrm{g} \mathrm{g}^{-1}$ for MIT and CMIT respectively. Three different adhesive samples were successfully analyzed. The procedure was compared with the direct analysis using UPLC-QTOF, where the identification of the compounds and the quantification values were confirmed. The results obtained are shown and discussed.
\end{abstract}

